\title{
The Gas Ionization by Plasma Technology for Noninvasive Techniques in Oculoplastic
}

\author{
Tsioumas G Sotiris ${ }^{1 *}$, Georgiadis Nikolaos ${ }^{2}$ and Georgiadou Irini ${ }^{3}$ \\ ${ }^{1}$ University of Camerino, Greece \\ ${ }^{2}$ Department of Ophthalmology, Aristotle University of Thessaloniki, Greece \\ ${ }^{3}$ Department of Aesthetic Medicine, Aristotle University of Thessaloniki, Greece
}

Submission: February 11, 2017; Published: March 14, 2017

*Corresponding author: Tsioumas G Sotiris, Private Clinic, Diagnostic Clinic and Aesthetic Surgery Ophthalmology, Eye surgeon-Oculoplastic, President of Hellenic Society of Aesthetic Medicine and Non Invasive Surgery, Professor of University of Camerino for Aesthetic Medicine, Greece, Email: ofthalmoplastiki99@hotmail.com

\section{Abstract}

Purpose: The objective of the research is to highlight the new non -invasive techniques there are in oculoplastic using plasma technology ( $4^{\text {th }}$ stage of matters, gas ionization) aimed at resolving multiple eyesores problems in the ophthalmic area. We will talk about how through new techniques in oculoplastic we can solve problems like, xanathelasmas, Hemangiomas, eyelidcysts, ektropion, entropion, scars, syrignomas, papillomas, benign tumors, chalazion and benign tumors in difficult areas such as gray line.

Method: The methodology that is followed to solve the above-mentioned cases is the use of Plasma Exeresis using PLEXR machine. After first diagnosis and analysis in each region, we proceed to address and resolve the musing the Plasma Exeresis. The techniques of Plasma Exeresis are either spot by spot or spray method, depending on the case. There is no use of searing iron, the area is not cauterized but sublimated without complications, without scarring, and without affecting the optic nerve.

Results: Complete resolution of problem areas from the first session without the phenomena of recurrence. In case such as ektropion and entropion resolve can occur after 2-3 sessions.

Conclusion: In the past the solution to such problems requires surgical rooms, microscopes, stitches, and long period of recuperation. Now not only the patient can bloodlessly, more economically, without surgery and rehabilitation to get rid of these specific problems but also the doctor to perform all these methods, without complications in his clinic.

\section{Introduction}

In 2017, due to the fact that the advancements in the medical industry are changing rapidly, the need for direct and non-painful solutions to problems patients is increasing. The Exeresis Plasma method comes to cover this need because the use of it becomes necessary at the Oculoplastic and at the ophthalmology field. Now the doctor can proposing outright solutions to the patient without mentioning the word surgery thus eliminate the fear of the patient for the surgery. Our aim is to showthe new bloodless techniques in oculoplastic that their effectiveness equals that of surgery but without the complications and discomfort that may occur from a surgery [1-3].

\section{Diagnosis}

We examined and studied 347 patients who were experiencing problems as xanthelasmas (38), hemangiomas (4), eyelid cysts (20), entropion (2) ektropion (10), syrignomas (100), papillomas (100) benign nodules (45), chalazion (8) and benign tumors in difficult areas such as the gray line (20). The age range is from 25-78 years of age, smoking and non-smoking men and women. All incidents had as common fact the fear of surgery that is why the suggestive method was with Plasma Exeresis [3-6] (Figure 1).

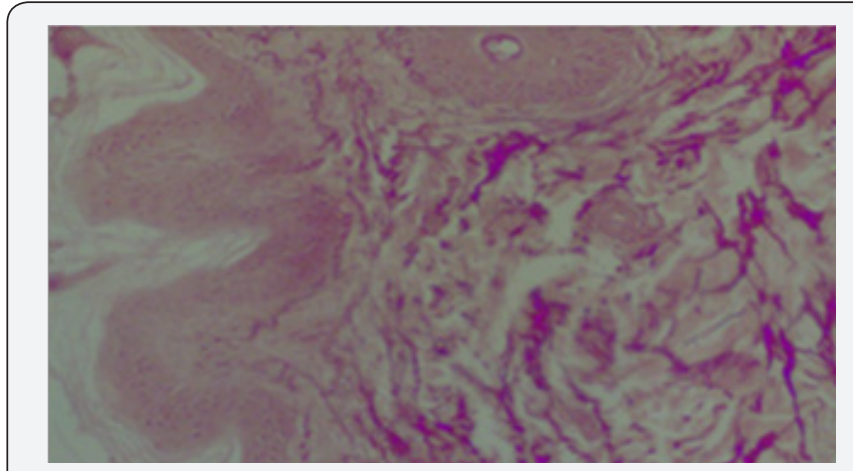

Figure 1 


\section{Method}

All patients accepted antisepsis in the areas that we would apply the Exeresis Plasma method. Then in all cases, except from those of ektropion, entropion, chalazion and benign tumors in the gray line, we applied numbing cream for 30 minutes. After the 30 minutes we removed the cream and started the process. The area was anesthetized and the patient did not felt anything during the treatment. In cases of ektropion, entropion, chalazion and benign tumors in the gray line, applied numbing injection with xylocaine [6-9].

Once anesthetized the area either with anesthetic cream or anesthetic injection we started implementing Plasma Exeresis. For implementing the method we used Plexr machine which has three pistols with different intensity. Those pistols do not use electric power and they are not connected with cables. Depending on the site and the problem, we use the corresponding pistol. Sublimation methods are 2. Spot by spot method or Spray Method. All cases were treated with the two methods either separately or in combination $[10,11]$ (Figure 2).

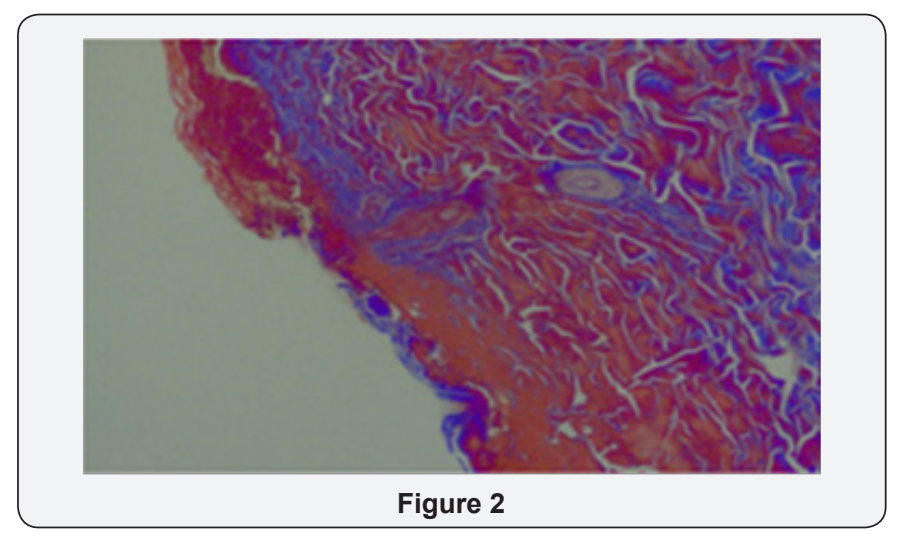

Analysis

A. Xanthelasmas: Spray Method

B. Hemangiomas: Spot by spot method

C. Cysts: depending on the shape and size of the cyst, combination of 2 methods.

D. Ektropion-Entropion : Spot by spot with specific direction

E. Scars: Combination of 2 techniques depending on the scar

F. Syrrigkoma: Spot by spot Method

G. Papillomas: depending on the size either Spray Method or Spot by Spot Method

H. Benign Tumors: Spot by spot around the tumor to anesthetize the area and then Spray method to sublimate the tumor

I. Chalazio: If it's in the gray line follow the spray method, if it is in tarsus use the spray method and the spot by spot method combined

J. Benign tumors at the gray line: Spray Method

\section{Results}

The result in all cases is the complete sublimation of the problems from the first session, without scarring, sutures, and long recovery periods. In cases of ectropion and entropion we may need a second session depending on the degree of ectropion / entropion ( $2^{\text {nd }}$ or $3^{\text {rd }}$ degree). Using Plasma Exeresis method is effective not only because the patient avoids surgery having the same effect with less cost but also for histological reasons. Histological analyzes before and after show that in regions that was applies Plasma Exeresis, the area not only reconstructed but created and type collagen III after application [12,13] (Figure 3 \& 4).
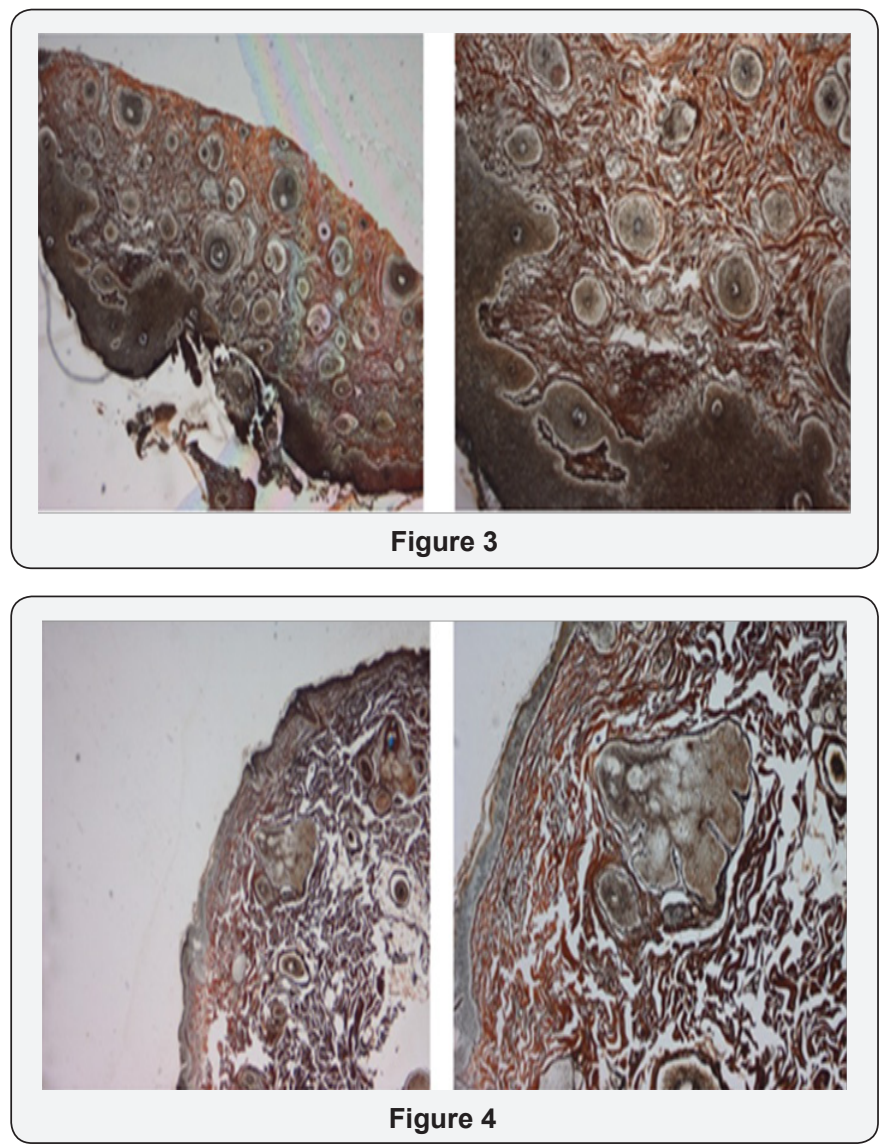

\section{Conclusion}

After 347 successful cases in 1 year period, it is a fact that now every doctor can provide permanent and effective treatments to the patient using the Plasma technology (ionization of gas$4^{\text {th }}$ station of matter) in his clinic. The patient with low cost and without the fear of surgery solves his problem without blood, stitches and painful procedures. Finally it is worth to mention that the use of Plasma analysis is not only effective in ophthalmology and in other specialties as well. 


\section{References}

1. Ceccarelli M In vecchiamento generale e cutaneo in medicina Estetica.

2. Alberto Massirone (2010) Trattato dimedicinaestetica Piccin PiccinNuova Libraria, Italy.

3. Sebben JE (1989) Cutaneous electrosurgery. Year Book Medical Publishers, Chicago, USA.

4. Hainer BL (1991) Fundamentals of electrosurgery. J Am Board Fam Pract 4(6): 419-426.

5. Georgia Gloustianou, Maria Sifaki, Sotiris G Tsioumas, Vlachodimitropoulos, Antonio Scarano (2016) "Presentation of Old and New Histological Results after Plasma Exercises (Plexr) Application (Regeneration of The Skin Tissue With Collagen III)". Pinnacle Medicine \& Medical Sciences 3(3): 983-990.

6. Geleki Stamatina, Tsioumas Sotiris, Vranou Aglaia (2015) "Plexr In Acne Treatment” Pinnacle Medicine \& Medical Sciences 2(1): 482-486.

7. Tsioumas G Sotiris, Georgiadou Irini, Ntountas Ioannis (2014) "Noninvasive Upper Blepharoplasty In relation to Surgical Blepharoplasty" Pinnacle Medicine \& Medical Sciences 1(5): 436-440.

8. Tsioumas G Sotiris, Georgiadis Nikolaos, Georgiadou Irini (2014) "Plexr: The Revolution in Blepharoplasty" Pinnacle Medicine \& Medical Sciences 1(5): 423-427.

This work is licensed under Creative Commons Attribution 4.0 License

DOI: $10.19080 /$ JOJO.2017.02.555584
9. Tsioumas G Sotiris, Vlachodimitropoulos Dimitris, Goutas Nikolaos (2015) “Clinical and Histological Presentation After Plexr Application, Needle Shaping (Vibrance) and OFF" Pinnacle Medicine \& Medical Sciences 2(3): 522-530.

10. Tsioumas G Sotiris, Chorozidis Ioannis, Papapostolou Apostolos (2015) "The Efficiency of Vibrance (Needle Shaping) and OFF (Non surgical Dermal Ablative Treatment) on Body Reshaping" Pinnacle Medicine \& Medical Sciences 2(2): 506-509.

11. Tsioumas G Sotiris, Chorozidis Ioannis, Zografaki Irini (2015) "The Induction of Lipolysis Using The Machine of O.F.F (Bags Under The Eyes) and The Application of Needle Shaping Technique Using The Vibrance Machine (Tear Through)" Pinnacle Medicine \& Medical Sciences 2(1): 445-448.

12. Tsioumas G Sotiris, Chorozidis Ioannis, Varvarezou-Liliou Anastasia (2015) "Comparison of The Efficacy of Injectable Hyaloronic Acid Versus Needle Shaping (Vibrance) and OFF (Onde Flusso Frazionato) For The Aesthetic Treatment of The Face" Pinnacle Medicine \& Medical Sciences 2(1): 441-444

13. Scarano F, Carinci B, Sinjari L, Artese G, Fippi G, Brunelli R, Monguzzi (2011) "European Journal Of Inflamation" 9(3): 89-94.

Your next submission with Juniper Publishers will reach you the below assets

- Quality Editorial service

- Swift Peer Review

- Reprints availability

- E-prints Service

- Manuscript Podcast for convenient understanding

- Global attainment for your research

- Manuscript accessibility in different formats ( Pdf, E-pub, Full Text, Audio)

- Unceasing customer service

Track the below URL for one-step submission _https://juniperpublishers.com/online-submission.php 